\title{
Round Ligament
}

National Cancer Institute

\section{Source}

National Cancer Institute. Round Ligament. NCI Thesaurus. Code C12319.

Any of the round ligaments including the round ligament of the liver and the round ligament of the uterus. 